\title{
A tradition and an epidemic: determinants of the campylobacteriosis winter peak in Switzerland
}

\author{
Philipp Justus Bless • Claudia Schmutz • \\ Kathrin Suter $\cdot$ Marianne Jost $\cdot$ Jan Hattendorf • \\ Mirjam Mäusezahl-Feuz • Daniel Mäusezahl
}

Received: 6 March 2014/ Accepted: 15 May 2014/Published online: 3 July 2014

(c) The Author(s) 2014. This article is published with open access at Springerlink.com

\begin{abstract}
Campylobacteriosis is the most frequently reported food borne infection in Switzerland. We investigated determinants of infections and illness experience in wintertime. A case-control study was conducted in Switzerland between December 2012 and February 2013. Cases were recruited among laboratory-confirmed campylobacteriosis patients. Population-based controls were matched according to age group, sex and canton of residence. We determined risk factors associated with campylobacteriosis, and help seeking behaviour and illness perception. The multivariable analysis identified two factors associated with an increased risk for campylobacteriosis: consumption of meat fondue (matched odds ratio [mOR] 4.0, $95 \%$ confidence interval [CI] 2.3-7.1) and travelling abroad (mOR 2.7, $95 \%$ CI 1.1-6.4). Univariable analysis among meat fondue consumers revealed chicken as the type of meat with the highest risk of disease (mOR 3.8, $95 \%$ CI 1.1-13.5). Most frequently reported signs and symptoms among patients were diarrhoea (98\%), abdominal pain $(81 \%)$, fever (66\%), nausea (44\%) and vomiting (34\%).
\end{abstract}

Philipp J. Bless and Claudia Schmutz have contributed equally to this paper.

P. J. Bless - C. Schmutz - K. Suter · J. Hattendorf .

D. Mäusezahl ( $\square)$

Swiss Tropical and Public Health Institute, Socinstrasse 57, 4002 Basel, Switzerland

e-mail: daniel.maeusezahl@unibas.ch

P. J. Bless $\cdot$ C. Schmutz $\cdot$ K. Suter $\cdot$ J. Hattendorf

D. Mäusezahl

University of Basel, Petersplatz 1, 4003 Basel, Switzerland

M. Jost · M. Mäusezahl-Feuz

Federal Office of Public Health, Schwarztorstrasse 96,

3003 Bern, Switzerland
The median perceived disease severity was 8 on a 1 -to- 10 rating scale. Patients reported a median duration of illness of 7 days and $14 \%$ were hospitalised. Meat fondues, mostly "Fondue chinoise", traditionally consumed during the festive season in Switzerland, are the major driver of the epidemic campylobacteriosis peak in wintertime. At these meals, individual handling and consumption of chicken meat may play an important role in disease transmission. Laboratory-confirmed patients are severely ill and hospitalisation rate is considerable. Public health measures such as decontamination of chicken meat and improved food handling behaviour at the individual level are urgently needed.

Keywords Campylobacter - Notification system - Casecontrol study · Switzerland · Gastroenteritis · Food borne diseases

\section{Introduction}

In recent years, campylobacteriosis emerged as the most commonly reported zoonosis in Europe, including Switzerland [1,2]. In 2012, the notification rate was 106 cases per 100,000 population corresponding to 8,567 laboratory confirmed cases [3], the highest rate since campylobacteriosis became a notifiable disease in 1988 [1]. By registering only laboratory-confirmed cases, substantial underreporting is very likely.

Human Campylobacter infections generally lead to selflimiting, acute gastroenteritis with diarrhoea, abdominal pain, fever, vomiting and bloody stool as commonly reported symptoms [4]. Patients suffering of a severe infection and pregnant or immunocompromised patients require antibiotic treatment [5]. Rare but serious sequels of 
Campylobacter infections include reactive arthritis, febrile convulsions and Guillain-Barré syndrome [4] and contribute considerably to morbidity and economic costs of campylobacteriosis [6, 7]. Varying case-definitions, targeted age groups and co-morbidities, methodologies, and follow-up periods result in a broad range of reported casefatality rates. Risk factors for sporadic and outbreak-related Campylobacter infections have been extensively studied $[8,9]$. Some 50-80 \% of sporadic human Campylobacter infections are attributable to chicken as a reservoir either through transmission via handling and consumption of poultry, eating undercooked poultry or via contact with live poultry [10-14]. Recent case-control studies identified chicken consumption as source of infection for 24-29\% of all cases [14]. Similarly, consuming chicken is an attributable risk exposure for $27 \%$ of campylobacteriosis cases in Switzerland [15]. Indirect evidence for an association between chicken consumption and human campylobacteriosis is provided by: (1) a significant reduction of campylobacteriosis case notifications after large-scale marketwithdrawals of chicken due to dioxin-contaminated feed components [16] or an avian influenza outbreak [17] and (2) congruent seasonality patterns of the incidence of campylobacteriosis in humans and Campylobacter colonisation of broiler flocks [18]. Other reported exposure risks originate from drinking unsafe water, consuming raw milk and unpasteurised dairy products, eating barbecued meat, travelling abroad and from contact with farm animals and pets [2, 8, 9]. Campylobacteriosis outbreaks in Europe are rare, accounting for about $2 \%$ of campylobacteriosis cases only $[14,19]$. They are mostly associated with consumption of contaminated drinking water, raw milk and chicken products [9, 19, 20].

In temperate regions, seasonal patterns of human campylobacteriosis exist with an increased incidence during summer months [21, 22]. In Switzerland and Germany, seasonal patterns exhibit two distinct peaks: one in summer and one in winter $[1,23]$. Reasons for this remain speculative: in Switzerland, suspected causes for both peaks include handling of raw and consumption of undercooked meat from barbecuing and from preparing a traditional meat fondue, a festive Christmas and New Year's dish, which implicates the handling of raw meet by the consumer at the table [1]. The objectives for this study were to investigate determinants of the campylobacteriosis winter peak in Switzerland and to elucidate illness perception, symptomatology, and help seeking patterns of campylobacteriosis patients.

\section{Methods}

A case-control study recruiting prospectively laboratoryconfirmed campylobacteriosis cases and population-based controls was conducted between December 2012 and February 2013.

The National Notification System for Infectious Diseases (NNSID) of the Swiss Federal Office of Public Health (SFOPH) covers entire Switzerland. Campylobacter infections must be mandatorily reported by diagnostic laboratories. Four private laboratories, covering entire Switzerland and diagnosing about one-third of all notified cases, participated in case recruitment from 21st December 2012 until 24th January 2013.

Considering the seasonal nature of Campylobacter infections, the study commenced after the SFOPH enacted that the mandatory notifications of participating laboratories had to include person-identifiable data as stipulated by the Swiss Epidemics Act.

\section{Cases}

All cases reported by the four laboratories to the NNSID were screened for eligibility. Eligibility criteria for cases were age $\geq 5$ years and Swiss residency. Cases were excluded if they reported antibiotic treatment 4 weeks prior to disease onset or were not speaking German, French or Italian.

\section{Controls}

Controls were selected from a random sample of the Swiss population obtained from the Federal Statistical Office. They were matched for sex, age group and canton of residence. Controls were excluded if they reported a diarrhoeal illness 4 weeks prior to the corresponding case's disease onset. In addition, the same exclusion criteria as for cases were applied.

\section{Sample size}

The study was designed to detect an effect size [odds ratio (OR)] of 2.5, with a power of $80 \%$ at a two-sided significance level of 0.05 assuming a case-to-control ratio of 1:1. Rejection rates were estimated at $50 \%$ for cases and $75 \%$ for controls. To achieve a sample size of 100 cases and 100 controls and to account for refusals and for exclusions after enrolment, sampling foresaw contacting 300 cases and 600 controls. All eligible controls were included, resulting in a case-to-control ratio ranging from $1: 1$ to $1: 4$.

\section{Recruitment process}

Within $24 \mathrm{~h}$ upon receiving a positive laboratory report we sent an information letter together with a photo-illustrated questionnaire to the case by priority mail. The same package was mailed to four matched controls within $24 \mathrm{~h}$ 
after completion of the case interview. Following the written notice cases and controls were contacted by telephone and, after giving verbal consent to participate, either interviewed immediately or a suitable appointment for the interview was fixed. If controls refused participation, additional controls were selected until at least one per case could be interviewed. Cases and controls were excluded after 15 unsuccessful call attempts or if no telephone number was available in the telephone directory or upon request via postal mail. For participants $<15$ years, letters were sent to their parents and either parent was interviewed as surrogate.

\section{Questionnaire}

The questionnaire comprised a section on food- and nonfood exposures and, for cases, a part on illness experience. It contained questions regarding food consumption, origin of meat, eating and hygiene behaviour, contacts to animals and humans, knowledge about food borne pathogens, recent travel history, occupational exposure and co-morbidity. For both, cases and matched controls, exposure information was collected for the 7 days preceding the onset of the case's disease, except for travel history (preceding 2 weeks). For case interviews, the questionnaire addressed morbidity, health seeking behaviour and treatment. Computer-assisted telephone interviews using LimeSurvey software were performed. In parallel, participants were encouraged to follow the interview questions in the photo-illustrated questionnaire.

\section{Statistical analyses}

Collected data were exported to Stata 10.1 (Stata Corporation). Pair-matched analyses were performed where applicable and matched odds ratios (mOR) are presented. Univariable conditional logistic regressions were performed. Variables with cells containing zero values in contingency tables were analysed using exact logistic regression.

For the multivariable conditional logistic regression we considered variables with $p \leq 0.2$ in the univariable analysis. In case of correlated predictor variables only the one which was biologically more plausible was kept in the model. In addition, we performed a subgroup analysis investigating risk factors among persons who reported fondue consumption.

The population attributable fraction (PAF) was calculated for each statistically significant risk factor of the multivariable model as difference of nationwide observed cases and expected cases in absence of the risk factor. Expected cases were calculated using the multivariable $\mathrm{mOR}$, frequency of exposure among cases and controls and the sex-, age- and canton-specific prevalence of Campylobacter notifications during the study period.

Subsequent exploratory data analysis including additional subgroup and stratified analyses was conducted in order to assist in the interpretation and to generate new hypotheses. When conditional analysis was not possible the results are presented descriptively.

\section{Results}

Response rate and basic characteristics of study participants

A total of 303 campylobacteriosis case notifications were received by the study team. After exclusion of cases $<5$ years and non-Swiss residency, 289 cases and 898 controls were invited to participate in the study (Fig. 1). We enrolled $180(62 \%)$ cases and $324(36 \%)$ controls of which $159(55 \%)$ cases and $280(31 \%)$ controls were included in the analysis. Case-to-control matching ratios were $1: 1$ for $72,1: 2$ for $57,1: 3$ for 26 and 1:4 for 4 cases, respectively. Participating cases represented $15 \%$ of all registered laboratory-confirmed campylobacteriosis cases during the study period.

The median number of call attempts was 2 for cases and 3 for controls. The median time period for cases between disease onset and interview was 15 days (range 5-63 days). Median age of participants was 38 years and the sex ratio was close to unity. Both study groups were consistent with regard to most socio-demographic characteristics (Table 1). An imbalance was observed in nationality as only $8(5.0 \%)$ cases compared to 40 (14.3\%) controls were not Swiss nationals.

Risk factors for campylobacteriosis during the festive season

\section{Univariable conditional logistic regression analysis}

Among foods consumed during the week prior to disease onset, meat consumption was identified as significant risk factor (mOR 5.2, $95 \%$ confidence interval [CI] 1.2-23.3), but the only type of meat significantly associated with an increased risk was chicken (mOR $2.595 \%$ CI 1.5-4.1) (Fig. 2). Eating raw or undercooked meat was associated with increased risk of disease (mOR 1.6, $95 \%$ CI 1.0-2.6); however the effect was not statistically significant. Conversely, the consumption of raw vegetables was significantly associated with a decreased risk (mOR 0.4, $95 \% \mathrm{CI}$ 0.2-0.7). In addition, the consumption of dried and smoked meat (mOR 0.6, $95 \%$ CI 0.4-0.9) and the consumption of 


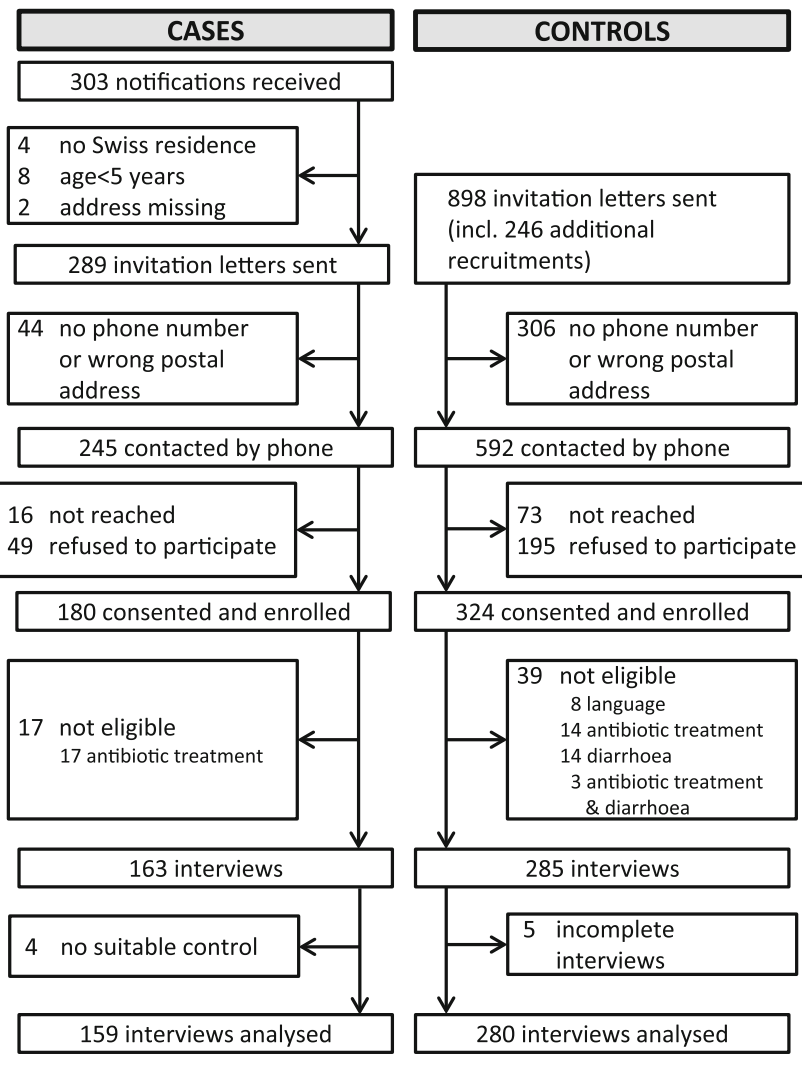

Fig. 1 Study profile of participants enrolled and recruited in the case-control study on Campylobacter infections in Switzerland, December 2012-February 2013

ham (mOR 0.6, $95 \%$ CI 0.4-1.0) were associated with a decreased risk.

The consumption of meat fondue was identified as a strong risk factor for disease (mOR 3.9, $95 \%$ CI 2.4-6.4). The most frequently consumed meat fondue variant, the socalled "Fondue chinoise", was also strongly associated (mOR 2.9, $95 \%$ CI 1.8-4.7).

The univariable analysis showed no significant association of travelling abroad (mOR 1.7, $95 \%$ CI 0.8-3.4) and campylobacteriosis. Having contact with children $<5$ was significantly associated with a decreased risk of illness (mOR 0.5, $95 \%$ CI 0.3-0.8). No significant association of the disease with occupational contacts involving ill persons, animals and children, raw and cooked foods was found. The same observation was made for non-occupational contacts to animals. Swiss nationality was associated with a significantly increased risk of disease (mOR 3.1, $95 \%$ CI 1.4-6.7). People with high education were less likely to suffer from disease (mOR 0.7, $95 \%$ CI 0.4-1.1).

Among the fondue consumers, chicken showed again the strongest effect (mOR 3.8, $95 \%$ CI 1.1-13.5) of all meat types (Fig. 3). There was no noteworthy difference between
Table 1 Socio-demographic characteristics of 159 cases and 280 controls who participated in the case-control study on campylobacteriosis in Switzerland, December 2012-February 2013

\begin{tabular}{lcc}
\hline Characteristic & Cases, $\mathrm{n}(\%)$ & Controls, $\mathrm{n}(\%)$ \\
\hline Sex & & \\
Male & $77(41.6)$ & $143(51.1)$ \\
Female & & $137(48.9)$ \\
Age groups (years) & $10(6.3)$ & $20(7.1)$ \\
$5-9$ & $6(3.8)$ & $8(2.9)$ \\
$10-14$ & $11(6.9)$ & $18(6.4)$ \\
$15-19$ & $18(11.3)$ & $39(13.9)$ \\
$20-24$ & $15(9.4)$ & $24(8.6)$ \\
$25-29$ & $39(24.5)$ & $65(23.2)$ \\
$30-44$ & $36(22.6)$ & $61(21.8)$ \\
$45-59$ & $16(10.1)$ & $31(11.1)$ \\
$60-74$ & $8(5.0)$ & $14(5.0)$ \\
$75+$ & & $240(85.7)$ \\
Nationality & $151(95.0)$ & $40(14.3)$ \\
Swiss & $8(5.0)$ & $173(61.8)$ \\
Foreign & & $107(38.2)$ \\
Education $^{\mathrm{a}}$ & $109(68.6)$ & \\
Low education & $50(31.4)$ & \\
High education & &
\end{tabular}

${ }^{a}$ Low education implies none, compulsory and vocational education. High education implies high school degree, university degree or other higher education

fondue meals consumed at home, or outside home at friends or at restaurants. Five out of six participants who reported fondue consumption at other locations (e.g. at holiday or alpine huts) were cases. The consumption of previously frozen meat at a meat fondue was significantly associated with a decreased risk of disease (mOR 0.1,95\% CI 0.0-0.6). The type of plate used for raw and cooked meat at a meat fondue was significantly associated with campylobacteriosis: both, using one plate with compartments and using two separate plates were associated with a decreased risk of disease (plate with compartments: mOR 0.4, $95 \% \mathrm{CI}$ 0.1-1.1; two plates: mOR 0.2, $95 \%$ CI 0.1-0.6).

\section{Multivariable conditional logistic regression analysis}

While the mOR for meat fondue remained unchanged, the effect was lower for chicken consumption in general (mOR 1.4 vs. 2.5) and for Swiss nationality (mOR 2.1 vs. 3.1) (Fig. 4). In contrast, the observed association with travelling abroad was stronger (mOR 2.7 vs. 1.7). The estimated PAFs for the significant risk factors of the multivariable model were $51.9 \%$ (95 \% CI 31.4-68.5\%) for meat fondue and $13.5 \%$ (95\%-CI 1.1-33.5\%) for travelling abroad. 
Fig. 2 Univariable conditional logistic regression analysis of selected risk factors for campylobacteriosis in winter times (December 2012-

February 2013) in Switzerland.

${ }^{a}$ matched odds ratio,

b confidence interval,

c participants aged $\leq 15$ or $\geq 65$ years were excluded

General food items
Ate any meat
Ate beef
Ate veal
Ate pork
Ate chicken
Ate turkey
Ate lamb
Ate duck
Ate horse
Ate dried and smoked meat
Ate ham
Ate sausage
Ate raw/undercooked meat
Ate meat fondue
Ate fondue chinoise
Ate raw vegetables
Ate raw carrots
Ate raw cucumbers
Ate raw salad
Ate raw fennel
Ate raw cabbage
Ate raw mushrooms
Ate raw pepper
Ate raw tomatoes
Ate raw onions
Ate raw celery
Non-food exposures
Travelling abroad
Contact with children $<5$ years
Occupational contact to ill people
Occupational contact to children
Occupational contact to animals
Occupational contact to raw foods
Occupational contact to cooked foods
Contact to animals
Swiss nationality
High education
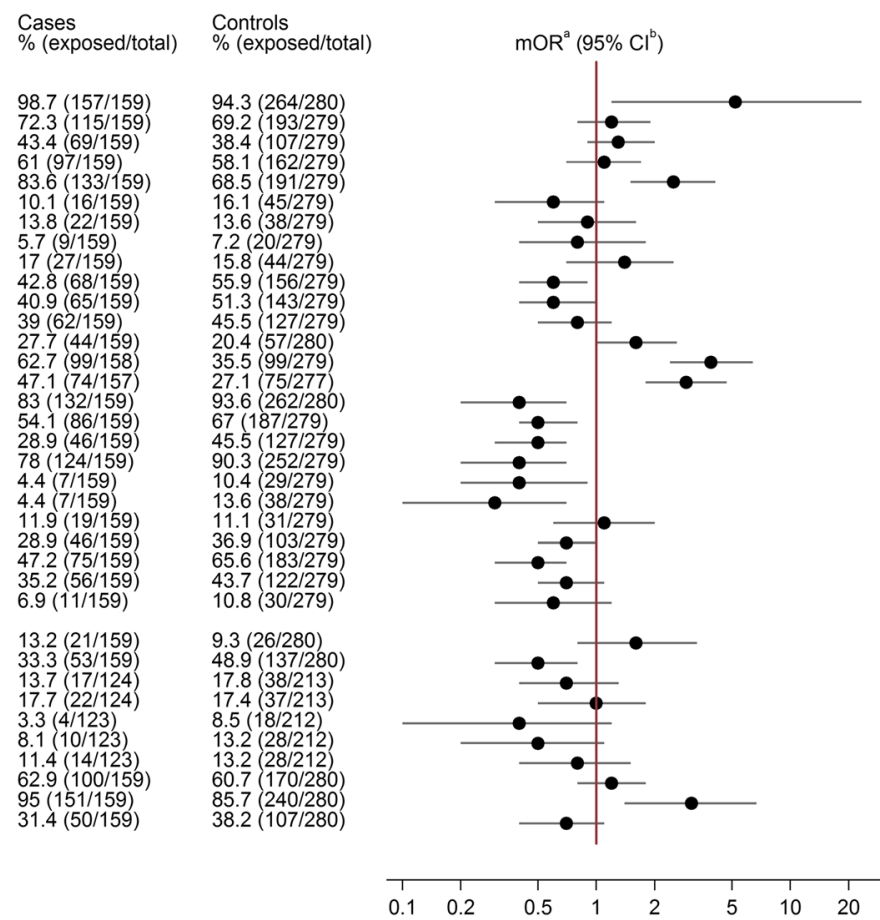

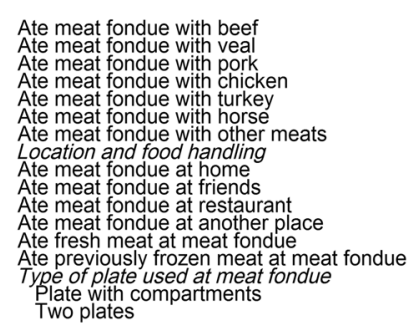

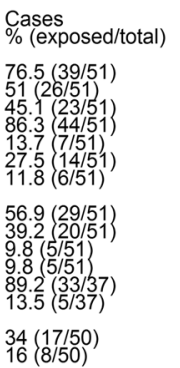

$34(17 / 50)$
$16(8 / 50)$
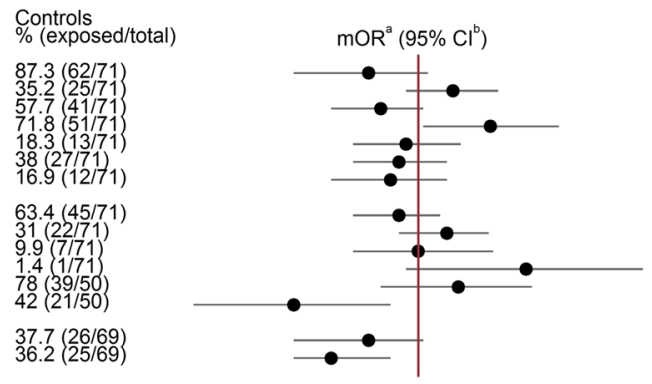

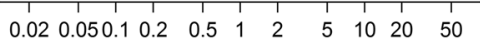

Fig. 3 Univariable conditional logistic regression analysis of selected risk factors for campylobacteriosis related to the consumption of meat fondue in winter times (December 2012-February 2013) in Switzerland. ${ }^{a}$ matched odds ratio, ${ }^{b}$ confidence interval

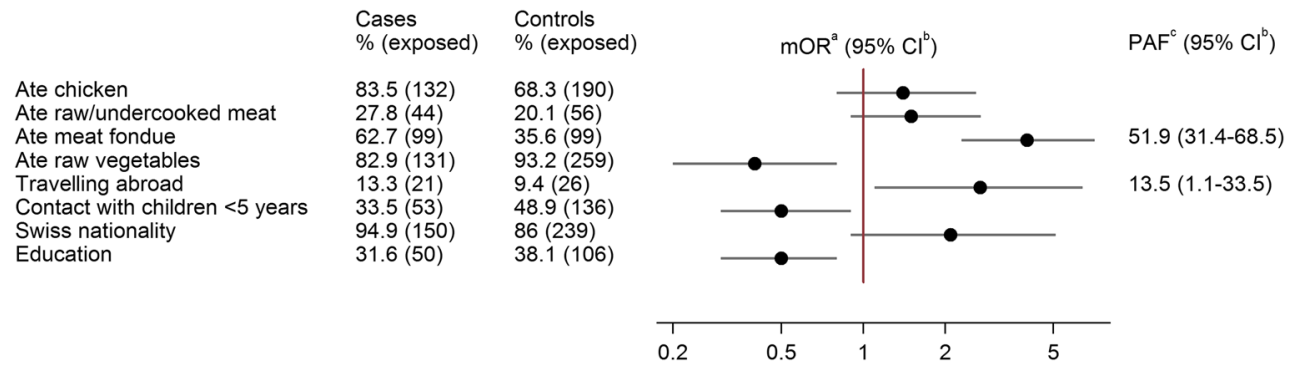

Fig. 4 Matched multivariable conditional logistic regression analysis of selected risk factors for 158 campylobacteriosis cases and 278 controls in winter times (December 2012-February 2013) in Switzerland. ${ }^{a}$ matched odds ratio, ${ }^{\mathrm{b}}$ confidence interval, ${ }^{\mathrm{c}}$ population attributable fraction

Exploratory subgroup and stratified analyses

The stratified analysis by sex revealed a significant difference in odds for the consumption of chicken meat between females (crude OR [cOR] 4.9, $95 \%$ CI 2.0-13.6) and males (cOR 1.4, $95 \%$ CI 0.7-2.9). Likewise, the consumption of meat fondue increased the odds for disease among females (cOR 5.6, $95 \%$ CI 2.9-10.8) significantly 
more compared to males (cOR 1.8, $95 \%$ CI 1.0-3.3). Out of 26 cases who did not eat chicken six reported the consumption of raw or undercooked meat $(23 \%$ in cases vs. $18 \%$ in controls), six reported meat fondue consumption with other meat types (23 vs. $15 \%$ ) but only a single person (case vs. 10 controls) reported travels abroad.

\section{Campylobacteriosis case characterisation}

Most frequently reported disease onset dates were December 27th/28th and January 2nd/3rd (Fig. 5). Median duration of illness was 7 days (range 2.5-33). Only half of all patients $(48 \%)$ reported full recovery. Most commonly reported signs and symptoms were diarrhoea, abdominal pain, fever, nausea, vomiting and headache (Table 2). Other reported symptoms included limb pain, shivering, fatigue, loss of appetite and vertigo. Irrespective of their sex, more than half of the patients rated the severity of their illness as 'severe' denoted by a median severity score of eight on a one-to-ten scale.

\section{First health care seeking}

Pharmacies and medical hotlines were consulted by 20 and $5 \%$ of the patients before seeing a physician, respectively. One third $(33 \%)$ of all patients had approached a physician directly. More than half (54\%) visited a physician within 3 days after symptoms onset. Most patients (63\%) visited a general practitioner (Fig. 5; Table 2). Emergency facilities were visited by $26 \%$ of patients.

\section{Hospitalisation}

The hospitalisation rate was $14 \%$ and did not differ between sexes, and was increased among patients $\geq 60$ years $(33 \%)$. Half of the hospitalisations lasted at least 3 nights.

\section{Pharmacotherapy}

With one exception, all patients reported drug treatment; about two-thirds received antibiotics. Other medications were applied for symptomatic treatment. Among the $24 \%$ of all patients who received an infusion for rehydration or intravenous drug application, $42 \%$ were in outpatient treatment.

\section{Discussion}

We assessed determinants for Campylobacter infections in wintertime in Switzerland with a case-control study design among laboratory-confirmed campylobacteriosis patients. A traditional meal (meat fondue), typically consumed at festive occasions in wintertime, was identified as the most important risk factor, especially if chicken meat was served. Furthermore, our findings suggest that the campylobacteriosis cases registered in the national disease registry are severely ill. The last investigation of determinants of campylobacteriosis in Switzerland dates back more than two decades and did not include the winter festive season [24].
Fig. 5 a Daily numbers of reported disease onsets of campylobacteriosis patients and b dates of consultations with a physician at an emergency facility or a general practice.

${ }^{\text {a }}$ Sunday/public holiday

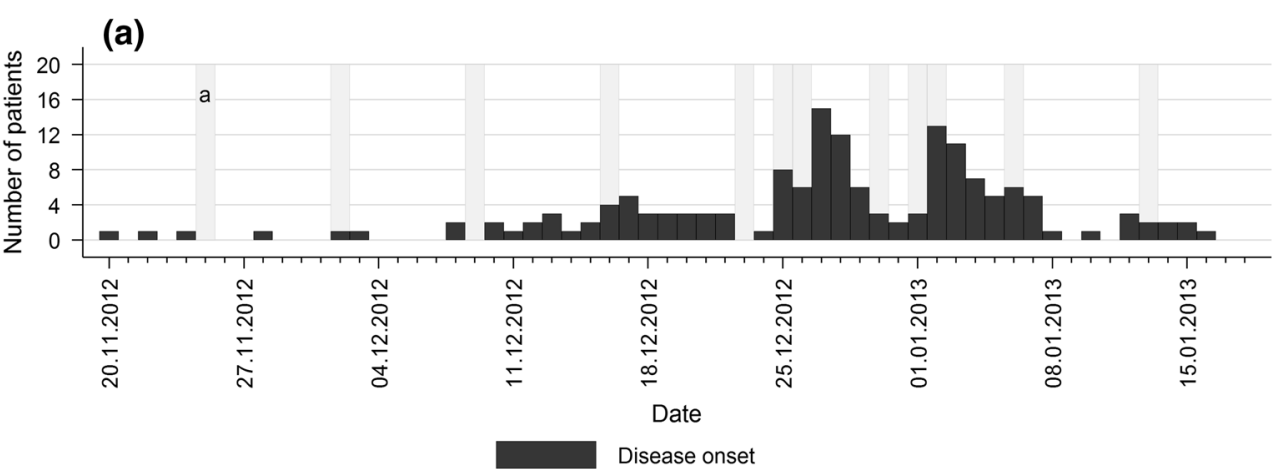

(b)

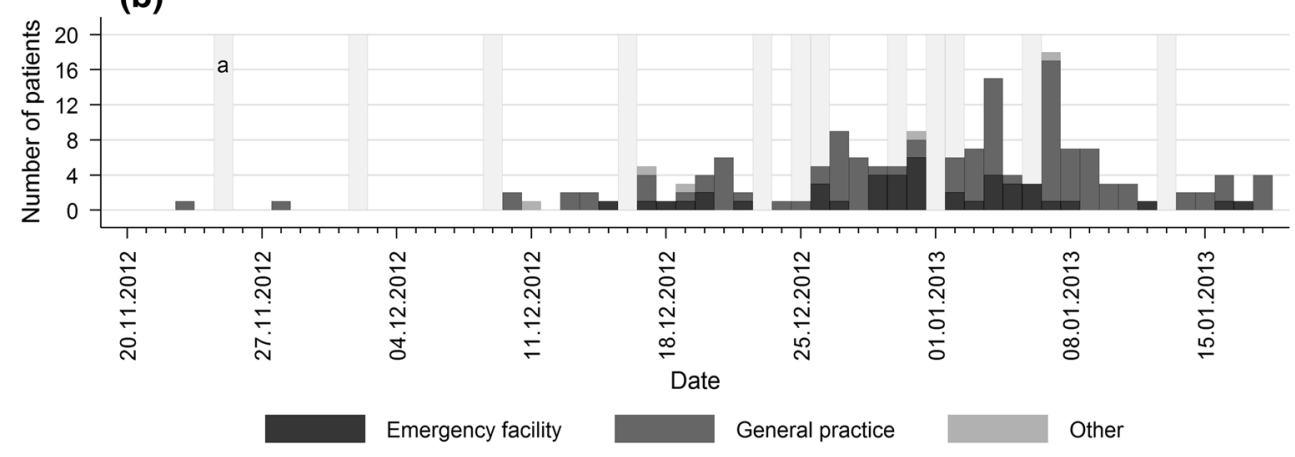


Table 2 Campylobacteriosis in Switzerland: reported duration of illness, signs and symptoms, perceived severity, medical treatment and medication, December 2012-February 2013

\begin{tabular}{|c|c|}
\hline & $\begin{array}{l}\mathrm{n}(\%) \text { or median } \\
\text { (range) } \\
(\mathrm{N}=159)\end{array}$ \\
\hline \multicolumn{2}{|l|}{ Campylobacter-associated morbidity } \\
\hline Duration of illness (days) ${ }^{\mathrm{a}}$ & $7(2.5-33)$ \\
\hline No recovery by the time of the interview & $43(27.0)$ \\
\hline Perceived severity of illness ${ }^{b}$ & $8(2-10)$ \\
\hline \multicolumn{2}{|l|}{ Symptoms ${ }^{\mathrm{c}}$} \\
\hline Diarrhoea & $156(98.1)$ \\
\hline Abdominal pain & $128(80.5)$ \\
\hline Fever & $105(66.0)$ \\
\hline Nausea & $70(44.0)$ \\
\hline Vomiting & $54(34.0)$ \\
\hline Headache & $20(12.6)$ \\
\hline \multicolumn{2}{|l|}{ Help seeking behaviour } \\
\hline \multicolumn{2}{|l|}{ Health care seeking before consulting a physician ${ }^{c}$} \\
\hline None: immediate consultation of a physician & $52(32.7)$ \\
\hline Pharmacy & $31(19.5)$ \\
\hline Medical hotline & $8(5.0)$ \\
\hline Friends and family & $68(42.8)$ \\
\hline Internet & $23(14.5)$ \\
\hline Health guide & $8(5.0)$ \\
\hline Other & $10(6.3)$ \\
\hline \multicolumn{2}{|l|}{ Medical care seeking } \\
\hline General practitioner (GP) & $100(62.9)$ \\
\hline Emergency department & $23(14.5)$ \\
\hline Emergency practice & $19(11.9)$ \\
\hline Paediatrician & $6(3.8)$ \\
\hline Medical specialist & $4(2.5)$ \\
\hline Other & $7(4.4)$ \\
\hline \multicolumn{2}{|l|}{ Reasons for medical care seeking ${ }^{c}$} \\
\hline Severe symptoms & $105(66.0)$ \\
\hline No amelioration & $70(44.0)$ \\
\hline Need of a medical certificate & $6(3.8)$ \\
\hline Other & $44(27.7)$ \\
\hline \multicolumn{2}{|l|}{ Hospitalisation } \\
\hline Total & $23(14.5)$ \\
\hline Males $^{\mathrm{d}}$ & $13(15.9)$ \\
\hline Females $^{\mathrm{e}}$ & $10(13.0)$ \\
\hline Number of nights in hospital & $3(1-13)$ \\
\hline \multicolumn{2}{|l|}{ Medication } \\
\hline Consumed drugs & $158(99.4)$ \\
\hline \multicolumn{2}{|l|}{ Drug classes $^{c}$} \\
\hline Antibiotic (Fluoroquinolones, Macrolides) & $98(61.6)$ \\
\hline Antidiarrhoeal (Loperamide, Charcoal) & $84(52.8)$ \\
\hline Probiotic (enterococci, saccharomyces) & $73(45.9)$ \\
\hline $\begin{array}{l}\text { Analgesic (Acetaminophen, Dipyrone, } \\
\text { NSAIDs) }\end{array}$ & $66(41.5)$ \\
\hline
\end{tabular}

Table 2 continued

\begin{tabular}{|c|c|}
\hline & $\begin{array}{l}\text { n }(\%) \text { or median } \\
\text { (range) } \\
(\mathrm{N}=159)\end{array}$ \\
\hline $\begin{array}{l}\text { Antiemetic (Domperidone, Metoclopramide, } \\
\text { Meclozine) }\end{array}$ & $17(10.7)$ \\
\hline Spasmolytics (Butylscopolamine) & $17(10.7)$ \\
\hline Acid blockers (Proton pump inhibitors) & $5(3.1)$ \\
\hline Parenteral rehydration and/or drug application & $38(23.9)$ \\
\hline $\begin{array}{l}\text { a } \text { Only those recovered at time of interview inc } \\
\text { b } \mathrm{N}=158 \\
\text { c } \text { Multiple answers possible } \\
{ }^{\text {d }} \mathrm{N}=82 \\
\text { e } \mathrm{N}=77\end{array}$ & luded $(\mathrm{n}=116)$ \\
\hline
\end{tabular}

Meat fondues, predominantly "Fondue chinoise", are consumed traditionally in Switzerland during dinners around Christmas and New Year. In our study, disease onset dates peaked 2-3 days after those events. This is in line with the incubation period of 2-5 days [4]. More than $50 \%$ of Campylobacter-related gastroenteritis can be attributed to the consumption of meat fondue during the study period. The "Fondue chinoise" comprises sliced raw meat being individually handled and boiled in a familyshared broth hotpot. In contrast to chicken none of the other meat types consumed during fondue dishes were associated with Campylobacter infections. This is coherent with other studies identifying chicken as a risk exposure [11,24-30]. This includes two outbreaks of Campylobacter infections in which meat fondue including chicken meat was the suspected source of infection [31]. Since Germans consume meat fondue with increased popularity on New Year's Eve rather than at Christmas [32-34] Campylobacter-contaminated chicken could also be the cause for the peak of infections observed by Schielke et al. [23] in early January.

Further we observed that meat fondue eaters who put their raw and cooked meat on the same plate were more likely to suffer from campylobacteriosis. Conversely, the use of a compartmented plate or using two separate plates appeared to be protective in our study and has been previously recommended [35]. Campylobacter spp. are quickly inactivated after dipping the sliced chicken meat into the boiling broth. Therefore, on-the-plate cross-contamination of boiled meat from raw chicken meat juice is the most probable transmission route especially considering the low infectious dose of Campylobacter spp. [36].We found women to have significantly higher odds than men 
for acquiring a Campylobacter infection after consumption of chicken meat or meat fondue. Among our study participants women consumed more often chicken at meat fondues than men which, however, does not explain the elevated risk.

The consumption of undercooked meat as a risk factor for campylobacteriosis is well known [11, 13, 27, 28, 37]. In our study the consumption of raw or undercooked meat was associated with campylobacteriosis especially in people not consuming meat fondue. We hypothesise that the strong effect of meat fondue consumption outweighs the known effect of raw or undercooked meat consumption and, therefore, is only statistically significant in the subgroup of people not consuming meat fondue. Travelling abroad was the only behavioural factor in the multivariable analysis significantly associated with increased odds for Campylobacter infections. This risk factor has been described previously for Switzerland [24] and other countries [11, 25, 26, 28, 30]. Further, almost all acute gastroenteritis patients with travel history are tested for gastrointestinal pathogens and are more likely to be diagnosed (personal communication).

One can argue that meat fondue represents an intermediate variable on the pathway from chicken consumption to Campylobacter spp. infection. Intermediate variables, if included in the multivariable analysis, might bias the estimates-usually towards the null. Therefore, we re-ran the regression models omitting meat fondue-consumption: as expected, chicken consumption showed a higher odds ratio (2.3) compared to the full model. The point estimates for all other variables remained similar, with the exception of travelling abroad which was associated with a smaller effect.

Factors associated with reduced risk of Campylobacter infections

The finding that a reduced risk of disease is associated with having contact to children $<5$ years is difficult to interpret; especially because a high incidence is noticed for this age-class in the NNSID [1]. Persons having contact with young children may differ in general and food hygiene and dietary habits [38]. High education was associated with a reduced risk of disease. The association with gastrointestinal diseases in high-income countries is discussed controversially [38-41]. Another factor associated with a decreased risk was the consumption of raw vegetables. Similar findings are described from several European countries and elsewhere [13, 25, 27, 28, 42] linking the protective effects of the consumption of raw vegetables to high amounts of antioxidants and carotenoids which act as bacterial growth inhibitors and generally increase immunity to infection. Several reports underscore that people who eat raw vegetables differ from others concerning cooking and eating preferences and behaviour $[13,25,27,28,42]$. The consumption of raw vegetables, especially during winter time, may reflect a generally healthy lifestyle [25, 27, 28, 42].

An exploratory subgroup analysis among meat fondue consumers indicates that consuming previously frozen meat is associated with a decreased risk of campylobacteriosis. Similar experiences were made in Iceland where the number of campylobacteriosis cases declined after freezing of meat originating from Campylobacter-infected broiler flocks [43]. In Switzerland, Baumgartner et al. [44] showed that chicken products were less contaminated with Campylobacter spp. after freezing,- - a finding which is corroborated by the studies in Iceland [45] and Norway [46].

In summary, risk and preventive factors in this study point at contamination risks upstream at food productionand downstream at retail- and consumer sides. Consequently, potential preventive risk reduction measures could be applied upstream and downstream: upstream -, through decontamination at slaughter using peracetic acid [47] resulting in a decreased bacterial load at retail level or freezing of chicken meat before reaching retail $[43,45,46]$. Downstream risk prevention measures could include improving consumer awareness in handling raw chicken meat additionally to the current hygiene notice on Swiss chicken meat packages.

Illness perception and treatment of acute campylobacteriosis

Patients suffering from Campylobacter infection reported typical symptoms of an acute gastroenteritis and a high perceived severity of illness. Comparable studies for Switzerland are lacking; however, the pattern is coherent with experiences from other countries [13, 48-51]. The reported severity of illness appears to be slightly higher compared to others [48]. Compared to other countries the proportion of hospitalised patients $(14 \%)$ was higher [13, 48] or slightly lower [52]. This variability could be due to differences in health systems, including differing notification criteria, case definitions and health care provider structures.

Although antibiotics are not generally recommended for treatment of campylobacteriosis more than $60 \%$ of our study patients received antibiotic treatment. In absence of information on the individual patient's medical history we cannot judge whether antibiotic use was medically indicated.

Generally, case-fatality rates in high-income countries range from 0.04 to $0.6 \%[2,52-54]$. We observed no death during our study. However, due to the similarity of epidemiological patterns in Europe Campylobacter-attributable mortality is likely to occur also in Switzerland [2, 54]. 
Strengths and limitations

We recruited all our cases from laboratory-confirmed campylobacteriosis patients registered in the NNSID. Patients with a mild course of disease are less likely to consult a physician or to be tested for campylobacteriosis and, hence, less likely to be notified. Participating laboratories were from the private sector only; therefore, the hospitalisation rate and the proportion of patients approaching emergency departments and policlinics directly may be underestimated. Similarly, recruiting cases from private laboratories, serving mainly general practitioners, could explain the imbalance in nationalities. Swiss nationals more often consult their general practitioners while non-Swiss are more likely to approach emergency departments. As expected, patients more often volunteered to participate in the study and contacted back the study team after initial contacting failed. Cases may remember their exposures more accurately than controls, since they might have been reflecting about what caused their illness. Nevertheless, "don't know" was answered equally often by cases and controls. In addressing potential biases from recalling exposure risks we applied photo-illustrated questionnaires.

\section{Conclusion}

The study provides strong evidence that the consumption of a national festive dish ("Fondue chinoise") is a risk factor for human campylobacteriosis in Switzerland. The main risks associated with this dish are probably twofold: firstly, chicken meat is frequently contaminated with Campylobacter spp. [44]. Secondly, the possibilities of and occasions for cross-contamination and ingestion of bacteria are manifold and the infection risk is exacerbated through individual food-handling at the table. Our findings, therefore, highlight the importance of food hygiene for chicken preparation and consumption at meat fondues. The steadily increasing number of notified campylobacteriosis cases, the high population attributable fraction for meat fondue and the previously unknown severity of illness and hospitalisation rate underline the relative importance for Swiss public health over the festive season and point toward the necessity for public health interventions. Prevention measures could include decontamination of chicken meat at slaughter resulting in a decreased bacterial load at retail level, freezing of chicken meat before reaching retail and improving consumer awareness in handling raw chicken meat.

Acknowledgments This work was supported by the Swiss Federal Office of Public Health (SFOPH). The authors acknowledge Dr.
Daniel Koch (Swiss Federal Office of Public Health) for his support to conduct this study and for reviewing the manuscript and Dr. Christian Schindler (Swiss Tropical and Public Health Institute) for his statistical advice. We thank Dr. Sabine Walser (Swiss Federal Office of Public Health) for her help in setting up and supporting the study, Dr. Marco Jermini (Cantonal Laboratory Ticino) for help in translating the questionnaire, Steven Paul and his team (Swiss Tropical and Public Health Institute) for setting up the IT infrastructure and $\mathrm{Mr}$ Andreas Birrer (Swiss Federal Office of Public Health) for his help with access to the notification data. The team of interviewers and all pilot and study participants are gratefully acknowledged. The authors thank the team of the Federal Statistical Office for providing the random sample of the general population.

Conflict of interest This study was supported by the SFOPH with a view to understand campylobacteriosis and how the disease presents in the general population. Marianne Jost and Mirjam Mäusezahl-Feuz are on the staff of the SFOPH and participated in their capacities as public health specialists and their function as scientific collaborators within the organisation. The SFOPH played no part in the study design, data collection, analysis and interpretation of the results. Philipp Bless, Claudia Schmutz, Kathrin Suter, Jan Hattendorf and Daniel Mäusezahl are on the staff of the Swiss Tropical and Public Health Institute and received funding (incl. for a student practical for CS) from the SFOPH.

Ethical statement The study was conducted under the Swiss Epidemics Act (SR 818.101 EpG). All participants were asked for oral informed consent before conducting the interview. The study was conducted in accordance with the Helsinki Declaration.

Open Access This article is distributed under the terms of the Creative Commons Attribution License which permits any use, distribution, and reproduction in any medium, provided the original author(s) and the source are credited.

\section{References}

1. Baumgartner A, Felleisen R, Gut C. Campylobacter in Switzerland-risk factors and measures for dealing with the problem. Governmental Report. Bern, Switzerland: Federal Office of Public Health 2012.

2. EFSA (European Food Safety Authority), ECDC (European Centre for Disease Prevention and Control). The European Union Summary Report on Trends and Sources of Zoonoses, Zoonotic Agents and Food-borne Outbreaks in 2011. EFSA J. 2013;11(4):3129. doi:10.2903/j.efsa.2013.3129.

3. Bundesamt für Gesundheit. Datendetails Campylobacteriose. 2014. http://www.bag.admin.ch/k_m_meldesystem/00733/00813/ index.html?webgrab_path=aHR0cDovL3d3dy5iYWctYW53Lm FkbWluLmNoL2luZnJlcG9ydGluZy9kYXRlbmRldGFpbHMv ZC9jYW1weWxvYmFjdGVyLmh0bQ\%3D\%3D\&lang=de. Accessed 06022014.

4. Braam HP. Campylobacter Enteritis. In: Heymann DL, editor. Control of communicable diseases manual. 18th ed. Washington: American Public Health Association; 2004. p. 81-4.

5. WHO Consultation on the Increasing Incidence of Human Campylobacteriosis, World Health Organization. Dept. of Epidemic and Pandemic Alert and Response. The increasing incidence of human campylobacteriosis: report and proceedings of a WHO consultation of experts, Copenhagen, Denmark, 21-25 November 2000. Geneva, Switzerland: World Health Organization 2001. 
6. Smith JL. Arthritis, Guillain-Barre-syndrome, and other sequelae of Campylobacter jejuni enteritis. J Food Protect. 1995;58(10): 1153-70.

7. Scharff RL. Economic burden from health losses due to foodborne illness in the United States. J Food Protect. 2012; 75(1):123-31. doi:10.4315/0362-028X.JFP-11-058.

8. Domingues AR, Pires SM, Halasa T, Hald T. Source attribution of human campylobacteriosis using a meta-analysis of casecontrol studies of sporadic infections. Epidemiol Infect. 2012;140(6):970-81. doi:10.1017/S0950268811002676.

9. Taylor EV, Herman KM, Ailes EC, Fitzgerald C, Yoder JS, Mahon BE, et al. Common source outbreaks of Campylobacter infection in the USA, 1997-2008. Epidemiol Infect. 2013;141(5): 987-96. doi:10.1017/S0950268812001744.

10. Lindmark H, Boqvist S, Ljungstrom M, Agren P, Bjorkholm B, Engstrand L. Risk factors for campylobacteriosis: an epidemiological surveillance study of patients and retail poultry. J Clin Microbiol. 2009;47(8):2616-9. doi:10.1128/JCM.00826-09.

11. Friedman CR, Hoekstra RM, Samuel M, Marcus R, Bender J, Shiferaw B, et al. Risk factors for sporadic Campylobacter infection in the United States: a case-control study in FoodNet sites. Clin Infect Dis. 2004;38(Suppl 3):S285-96. doi:10.1086/ 381598.

12. Mughini Gras L, Smid JH, Wagenaar JA, de Boer AG, Havelaar $\mathrm{AH}$, Friesema IHM et al. Risk factors for campylobacteriosis of chicken, ruminant, and environmental origin: a combined casecontrol and source attribution analysis. PLoS ONE. 2012;7(8): e42599. doi:10.1371/journal.pone.0042599.

13. Doorduyn Y, Van Den Brandhof WE, Van Duynhoven YT, Breukink BJ, Wagenaar JA, Van Pelt W. Risk factors for indigenous Campylobacter jejuni and Campylobacter coli infections in The Netherlands: a case-control study. Epidemiol Infect. 2010;138(10):1391-404. doi:10.1017/S095026881000052X.

14. EFSA Panel on Biological Hazards (BIOHAZ). Scientific Opinion on Quantification of the risk posed by broiler meat to human campylobacteriosis in the EU. EFSA J. 2010;8(1):1437. doi:10. 2903/j.efsa.2010.1437.

15. Buettner S, Wieland B, Staerk KD, Regula G. Risk attribution of Campylobacter infection by age group using exposure modelling. Epidemiol Infect. 2010;138(12):1748-61. doi:10.1017/ S095026881000155X.

16. Vellinga A, Van Loock F. The dioxin crisis as experiment to determine poultry-related Campylobacter enteritis. Emerg Infect Dis. 2002;8(1):19-22.

17. Friesema IH, Havelaar AH, Westra PP, Wagenaar JA, van Pelt W. Poultry culling and Campylobacteriosis reduction among humans, the Netherlands. Emerg Infect Dis. 2012;18(3):466-8. doi:10.3201/eid1803.111024.

18. Jore S, Viljugrein H, Brun E, Heier BT, Borck B, Ethelberg S, et al. Trends in Campylobacter incidence in broilers and humans in six European countries, 1997-2007. Prev Vet Med. 2010;93(1):33-41. doi:10.1016/j.prevetmed.2009.09.015.

19. Silva J, Leite D, Fernandes M, Mena C, Gibbs PA, Teixeira P. Campylobacter spp. as a Foodborne pathogen: a review. Front Microbiol. 2011;2:200. doi:10.3389/fmicb.2011.00200.

20. EFSA Panel on Biological Hazards (BIOHAZ). Scientific Opinion on Campylobacter in broiler meat production: control options and performance objectives and/or targets at different stages of the food chain. EFSA J. 2011;9(4):2105. doi:10.2903/j.efsa.2011. 2105.

21. Skirrow MB. Campylobacter. Lancet. 1990;336(8720):921-3.

22. Nylen G, Dunstan F, Palmer SR, Andersson Y, Bager F, Cowden $\mathrm{J}$, et al. The seasonal distribution of campylobacter infection in nine European countries and New Zealand. Epidemiol Infect. 2002;128(3):383-90.
23. Schielke A, Bettina RM, Stark K. Epidemiology of campylobacteriosis in Germany-insights from 10 years of surveillance. BMC Infect Dis. 2014;14(1):30. doi:10.1186/1471-2334-14-30.

24. Schorr D, Schmid H, Rieder HL, Baumgartner A, Vorkauf H, Burnens A. Risk factors for Campylobacter enteritis in Switzerland. Zentralbl Hyg Umweltmed. 1994;196(4):327-37.

25. Eberhart-Phillips J, Walker N, Garrett N, Bell D, Sinclair D, Rainger W, et al. Campylobacteriosis in New Zealand: results of a casecontrol study. J Epidemiol Commun Health. 1997;51(6):686-91.

26. Neal KR, Slack RC. Diabetes mellitus, anti-secretory drugs and other risk factors for campylobacter gastro-enteritis in adults: a case-control study. Epidemiol Infect. 1997;119(3):307-11.

27. Kapperud G, Espeland G, Wahl E, Walde A, Herikstad H, Gustavsen $\mathrm{S}$, et al. Factors associated with increased and decreased risk of Campylobacter infection: a prospective case-control study in Norway. Am J Epidemiol. 2003;158(3):234-42. doi:10.1093/ Aje/Kwg139.

28. Neimann J, Engberg J, Molbak K, Wegener HC. A case-control study of risk factors for sporadic campylobacter infections in Denmark. Epidemiol Infect. 2003;130(3):353-66.

29. Wingstrand A, Neimann J, Engberg J, Nielsen EM, Gerner-Smidt P, Wegener HC, et al. Fresh chicken as main risk factor for campylobacteriosis, Denmark. Emerg Infect Dis. 2006;12(2):280-4.

30. Stafford RJ, Schluter P, Kirk M, Wilson A, Unicomb L, Ashbolt $\mathrm{R}$, et al. A multi-centre prospective case-control study of campylobacter infection in persons aged 5 years and older in Australia. Epidemiol Infect. 2007;135(6):978-88. doi:10.1017/ S0950268806007576.

31. Bundesamt für Gesundheit. Epi-Notiz: Campylobacter à discrétion. BAG Bulletin. 2003;8.

32. Fehrmann C. Silvester und das Feiern am Fondue. Westdeutsche Zeitung. 2012. http://www.wz-newsline.de/lokales/kreis-viersen/ niederrhein/silvester-und-das-feiern-am-fondue-1.1191429. Accessed 01052014

33. t-online.de. Fondue-Praktische Tipps für den Silvester-Klassiker. t-online.de. 2012. http://www.t-online.de/ratgeber/familie/ familienleben/id_52322382/fondue-praktische-tipps-fuer-den-sil vester-klassiker.html. Accessed 01052014.

34. Lücke R. Das Fondue-ein kulinarischer Dauerbrenner. Welt Online. 2009. http://www.welt.de/lifestyle/article5624863/Das-Fon due-ein-kulinarischer-Dauerbrenner.html. Accessed 01052014.

35. Bundesamt für Gesundheit. Hygieneregeln bei der Zubereitung von Fondue Chinoise. 2011. http://www.blv.admin.ch/themen/04678/ 04817/04828/04829/index.html?lang=de. Accessed 06022014.

36. Kothary MH, Babu US. Infective dose of foodborne pathogens in volunteers: a review. J Food Saf. 2001;21(1):49-73.

37. Gallay A, Bousquet V, Siret V, Prouzet-Mauleon V, Valk H, Vaillant V, et al. Risk factors for acquiring sporadic Campylobacter infection in France: results from a national case-control study. J Infect Dis. 2008;197(10):1477-84. doi:10.1086/587644.

38. Simonsen J, Frisch M, Ethelberg S. Socioeconomic risk factors for bacterial gastrointestinal infections. Epidemiology. 2008;19(2):282-90. doi:10.1097/EDE.0b013e3181633c19.

39. de Wit MA, Koopmans MP, Kortbeek LM, Wannet WJ, Vinje J, van Leusden F, et al. Sensor, a population-based cohort study on gastroenteritis in the Netherlands: incidence and etiology. Am J Epidemiol. 2001;154(7):666-74.

40. Majowicz SE, Dore K, Flint JA, Edge VL, Read S, Buffett MC, et al. Magnitude and distribution of acute, self-reported gastrointestinal illness in a Canadian community. Epidemiol Infect. 2004;132(4):607-17.

41. Bytzer P, Howell S, Leemon M, Young LJ, Jones MP, Talley NJ. Low socioeconomic class is a risk factor for upper and lower gastrointestinal symptoms: a population based study in 15000 Australian adults. Gut. 2001;49(1):66-72. 
42. Rodrigues LC, Cowden JM, Wheeler JG, Sethi D, Wall PG, Cumberland $\mathrm{P}$, et al. The study of infectious intestinal disease in England: risk factors for cases of infectious intestinal disease with Campylobacter jejuni infection. Epidemiol Infect. 2001;127(2): 185-93.

43. Tustin J, Laberge K, Michel P, Reiersen J, Dadadottir S, Briem H, et al. A national epidemic of campylobacteriosis in Iceland, lessons learned. Zoonoses Public Health. 2011;58(6):440-7. doi:10. 1111/j.1863-2378.2010.01387.x.

44. Baumgartner A, Felleisen R. Market surveillance for contamination with thermotolerant campylobacters on various categories of chicken meat in Switzerland. J Food Protect. 2011;74(12): 2048-54. doi:10.4315/0362-028X.JFP-11-228.

45. Georgsson F, Thornorkelsson AE, Geirsdottir M, Reiersen J, Stern NJ. The influence of freezing and duration of storage on Campylobacter and indicator bacteria in broiler carcasses. Food Microbiol. 2006;23(7):677-83. doi:10.1016/j.fm.2005.10.003.

46. Sandberg M, Hofshagen M, Ostensvik O, Skjerve E, Innocent G. Survival of Campylobacter on frozen broiler carcasses as a function of time. J Food Prot. 2005;68(8):1600-5.

47. Nagel GM, Bauermeister LJ, Bratcher CL, Singh M, McKee SR. Salmonella and Campylobacter reduction and quality characteristics of poultry carcasses treated with various antimicrobials in a postchill immersion tank. Int J Food Microbiol. 2013;165(3):281-6. doi:10.1016/j.ijfoodmicro.2013.05.016.

48. Deckert AE, Reid-Smith RJ, Tamblyn S, Morrell L, Seliske P, Jamieson FB, et al. Burden of illness and factors associated with duration of illness in clinical campylobacteriosis. Epidemiol Infect. 2013;141(12):2536-46. doi:10.1017/S0950268813000332.

49. Inns T, Foster K, Gorton R. Cohort study of a campylobacteriosis outbreak associated with chicken liver parfait, United Kingdom. Euro Surveill. 2010;15(44).

50. Kapperud G, Lassen J, Ostroff SM, Aasen S. Clinical features of sporadic Campylobacter infections in Norway. Scand J Infect Dis. 1992;24(6):741-9.

51. Zilbauer M, Dorrell N, Wren BW, Bajaj-Elliott M. Campylobacter jejuni-mediated disease pathogenesis: an update. Trans $\mathrm{R}$ Soc Trop Med Hyg. 2008;102(2):123-9. doi:10.1016/j.trstmh. 2007.09.019.

52. Scallan E, Hoekstra RM, Angulo FJ, Tauxe RV, Widdowson MA, Roy SL, et al. Foodborne illness acquired in the United Statesmajor pathogens. Emerg Infect Dis. 2011;17(1):7-15. doi:10. 3201/eid1701.091101p1.

53. Barton Behravesh C, Jones TF, Vugia DJ, Long C, Marcus R, Smith K et al. Deaths associated with bacterial pathogens transmitted commonly through food: foodborne diseases active surveillance network (FoodNet), 1996-2005. J Infect Dis. 2011;204(2):263-7. doi:10.1093/infdis/jir263.

54. Gkogka E, Reij MW, Havelaar AH, Zwietering MH, Gorris LG. Risk-based estimate of effect of foodborne diseases on public health, Greece. Emerg Infect Dis. 2011;17(9):1581-90. doi:10. 3201/eid1709.101766. 